\title{
REVITALISASI PEMBELAJARAN IPS DALAM MENGEMBANGKAN KETERAMPILAN BERPIKIR KRITIS
}

\author{
Novidya Yulanda \\ Dosen Program Studi Pendidikan Ekonomi Universitas Indraprasta PGRI \\ E-mail : novidyayulanda@gmail.com
}

\begin{abstract}
Abstrak
Artikel ini berawal dari opini yang berkembang di kalangan peserta didik, orangtua dan masyarakat bahwa IPS itu merupakan mata pelajaran yang membosankan dan dianggap sepele. Sehingga IPS kurang populer dan menjadi mata pelajaran "kelas dua" dimata peserta didik dan orang tua. Padahal pada dasarnya IPS merupakan sebuah mata pelajaran yang sangat penting dalam meningkatkan dan mengembangkan kemampuan berpikir kritis peserta didik. Revitalisasi pembelajaran IPS dilakukan dengan memperbaiki kurikulum pendidikan IPS mulai dari konten (muatan) pembelajaran IPS , metode dan sumber pembelajaran IPS, serta revitalisasi dalam proses penilaian pembelajaran IPS. Revitalisasi ini diharapkan menjadi sebuah solusi mengembalikan mata pelajaran IPS kembali kepada tujuan awalnya yaitu untuk melatih dan meningkatkan hard skill dan soft skill salah satunya keterampilan berpikir kritis peserta didik sebagai bekal mereka dalam kehidupan bermasyarakat.
\end{abstract}

Kata kunci : revitalisasi, keterampilan berpikir kritis

\section{Abstract}

This article begins with a growing opinion among learners, parents and society that social studies is a subject that is boring and trivial. So that social studies is less popular and become the "second class" in the eyes of learners and parents. Though essentially social studies is a subject that is very important in improving and developing the critical thinking skills of learners. Revitalization of learning social studies is done by improving the social studies curriculum ranging from content (content) learning social studies, methods and learning resources social studies, and revitalization in the process of learning social studies assessment. This revitalization is expected to be a solution to restore social studies subjects back to the original goal is to train and improve the hard skill and soft skill one of the critical thinking skills of learners as their provision in social life

Keyword : revitalization, critical thinking

\section{PENDAHULUAN}

Pendidikan adalah suatu upaya untuk memanusiakan manusia. Undang-Undang No. 2 Tahun 2003 tentang sistem pendidikan nasional pasal 1 ayat (1) menegaskan bahwa :

"Pendidikan adalah usaha sadar dan terencana untuk mewujudkan suasana belajar dan proses pembelajaran agar peserta didik secara aktif mengembangkan potensi dirinya untuk memiliki kekuatan spiritual keagamaan, pengendalian diri, kepribadian, kecerdasan akhlak mulia, serta ketrampilan yang diperlukan dirinya, masyarakat, bangsa dan Negara." 
Dalam mencapai tujuan pendidikan nasional tersebut, guru sebagai salah satu instrumen yang sangat penting dalam proses pendidikan haruslah memiliki empat kompetensi, salah satunya kompetensi pedagogik. Pedagogik sebagai ilmu sangat dibutuhkan oleh guru, karena guru akan berhadapan dengan anak yang belum "dewasa". Tugas guru bukan hanya mengajar untuk menyampaikan atau mentransformasikan pengetahuan kepada para anak di sekolah, melainkan guru mengemban tugas untuk mengembangkan kepribadian anak didiknya secara terpadu.

Selain itu, guru bertugas untuk membentuk anak untuk memiliki mental yang kuat, sehingga anak sensitif terhadap masalah-masalah kemanusiaan, memiliki rasa simpati dan empati, dan memiliki keterampilan hidup agar anak mampu untuk menghadapi segala permasalahan hidupnya di dalam lingkungan keluarga, lingkungan sekolah dan lingkungan sosialnya baik dalam kapasitasnya sebagai mahluk individual maupun sebagai mahluk sosial. salah satu caranya adalah dengan melatih keterampilan berpikir kritis anak.

Di lingkungan sekolah keterampilan berpikir kritis dapat dikembangkan melalui beberapa mata pelajaran, salah satunya Ilmu Pengetahuan Sosial (IPS). Misi pembelajaran IPS mengacu pada pengembangan intelektual, sikap, dan moral peserta didik, sehingga esensi dasar pembelajaran IPS menitikberatkan pada aspek knowing, doing dan caring”. Namun, Harapan dan misi dari IPS dalam kaitannya dengan pengembangan peserta didik untuk menjadi manusia yang berkualitas dan memiliki wawasan kedepan, tampaknya masih jauh dari harapan. Kenyataan yang terlihati di lapangan, menunjukkan bahwa pola dan pengembangan pembelajaran IPS masih mengacu pada pola transfering pengetahuan belaka. Guru hanya berusaha memindahkan pengetahuan yang ada di kepalanya ke kepala siswa, tanpa memberikan kesempatan yang memadai kepada siswa untuk mengembangkan potensi dirinya.

Kondisi ini akhirnya membentuk suatu opini di kalangan peserta didik, orangtua dan masyarakat bahwa IPS itu merupakan mata pelajaran yang membosankan dan dianggap sepele. Sehingga IPS kurang populer dan menjadi mata pelajaran "kelas dua" dimata peserta didik dan orang tua. Oleh karena itu, guru IPS sebagai agen pendidikan harus memikirkan langkah- langkah dan membuat desain pembelajaran yang menarik agar opini bahwa IPS tidak penting dapat terbantahkan. 


\section{PEMBAHASAN}

National Council for Social Studies (NCSS,2010), mendefisikan IPS sebagai berikut:

"Social studies is the integrated study of the science and humanities to promote civic competence. Whitin the school program, socisl studies provides coordinated, systematic study drawing upon such disciplines as anthropology, economics, geography, history, law, philosophy, political science, psychology, religion, and sociology, as well as appropriate content from the humanities, mathematics, and natural sciences. The primary purpose of social studies is to help young people develop the ability to make informed and reasoned decisions for the public good as citizen of a culturally diverse, democratic society in an interdependent world."

Berdasarkan pengertian di atas, terlihat bahwa ilmu pengetahuan sosial merupakan sebuah ilmu yang mengkaji tentang manusia dengan segala aspeknya dalam sistem kehidupan bermasyarakat. Hal ini sangat berkaitan dengan pernyataan pusat kurikulum (2006) yang mengatakan bahwa ilmu pengetahuan sosial dirumuskan atas dasar realitas dan fenomena sosial yang mewujudkan suatu pendekatan interdisipliner dari aspek dan cabang-cabang ilmu-ilmu sosial seperti sosiologi, sejarah, geografi, ekonomi, politik, hukum dan budaya.

Tujuan utama social studies menurut NCSS (2010) adalah membantu generasi muda mengembangkan kemampuan pengetahuan dan keputusan yang rasional sebagai warga masyarakat yang beraneka budaya, masyarakat demokratis dalam dunia yang saling berketergantungan. Berdasarkan kajian dari beberapa penelitian dan pengamatan terhadap kehidupan sosial dan kebangsaan masa kini, terlihat bahwa kemampuan esensial yang diperlukan setiap warganegara dan bangsa Indonesia antara lain: baca, tulis, berkomunikasi, kreatif, peduli sosial dan lingkungan, demokratis, semangat kebangsaan, kebiasaan membaca, berpikir kritis, taat hukum, rasa ingin tahu, keinginan untuk selalu berkembang, beriman dan taqwa. Kemampuan-kemampuan ini seharusnya menjadi Standar Kompetensi Lulusan (SKL) yang harus dikembangkan oleh setiap mata pelajaran yang terdapat pada kurikulum SD, SMP, SMA, dan SMK. 
Revitalisasi pendidikan IPS merupakan salah satu cara untuk mengembalikan peran IPS sebagai mata pelajaran yang mampu untuk membangun dan mengembangkan kompetensi peserta didik yang memiliki kepedulian sosial dan kecakapan untuk menempatkan diri dalam sebagai anggota masyarakat melalui perbaikan materi dan kurikulum pembelajaran, metode pembelajaran, penggunaan sumber pembelajaran dan proses penilaian yang sesuai. Paul \& Elder (2007) menjelaskan bahwa "berpikir kritis merupakan cara bagi seseorang untuk meningkatkan kualitas dari hasil pemikiran menggunakan teknik sistemasi cara berpikir dan menghasilkan daya pikir intelektual dalam ide-ide yang digagas". Seseorang yang berpikir secara kritis akan dapat menjawab permasalahan- permasalahan yang penting dengan baik, dan dapat menggunakan ide yang abstrak untuk bisa membuat model penyelesaian masalah secara efektif. Beberapa kriteria yang dapat kita jadikan standar dalam proses berpikir kritis ini adalah kejelasan (clarity), tingkat akurasi (accuracy), tingkat kepresisian (precision) relevansi (relevance), logika berpikir yang digunakan (logic), keluasan sudut pandang (breadth), kedalaman berpikir (depth), kejujuran (honesty), kelengkapan informasi (information) dan bagaimana implikasi dari solusi yang kita kemukakan (implication).

Proses revitalisasi ini dimulai dari revitalisasi materi (konten) dan kurikulum, revitalisasi metode dan sumber pembelajaran serta revitalisasi proses penilaian dalam pembelajaran IPS.

\section{Revitalisasi Materi (Konten) Dan Kurikulum Pembelajaran IPS}

Guru sebagai agen pembelajaran di kelas dibekali dengan empat kompetensi, yaitu kompetensi pedagogik, kompetensi professional, kompetensi sosial, dan kompetensi kepribadian). Dengan menguasi keempat kompetesi ini, guru harus mampu memperbaiki proses pembelajaran yang dulunya berpusat kepada guru (teacher center) menjadi berpusat kepada peserta didik (student center). Selain itu, pemilihan materi juga sangat mempengaruhi proses pembelajaran, karena selama ini materi yang diberikan masih sangat konvensional (berupa teori, konsep, fakta, pendapat, dan sebagainya). Seharusnya pembelajaran IPS saat ini dikembangkan berdasarkan berbagai permasalahan yang ada dalam masyarakat di sekitarnya, (nasional, regional, dan dunia), seperti sikap dan perbuatan yang suka merusak, tingkat toleransi 
yang rendah, tingkat taat hukum yang rendah, tingkat harga diri yang rendah, kemiskinan, mental menerabas, tingkat mubazir yang tinggi dan tingkat produktivitas yang rendah, dan sebagainya dapat dikemas dan dijadikan materi substantif, (Hasan, 2007).

Kurikulum K-13 yang digunakan saat ini, juga telah memperbaiki pola pikir pembelajaran dari yang dulunya pasif menjadi pembelajaran kritis. Pola pembelajaran yang semula berpusat pada guru menjadi pembelajaran yang berpusat pada peserta didik, yang semula satu arah, menjadi pembelajaran interaktif. Kurikulum 2013 di susun dengan maksud antara lain untuk mengembangkan potensi peserta didik menjadi kemampuan dalam berpikir kritis dalam penyelesaian masalah sosial di masyarakat. Career Center Maine Department of Labor USA (2004) mengatakan bahwa pengembangan kemampuan berpikir kritis dan kreatif memang perlu dilakukan karena kemampuan ini merupakan salah satu kemampuan yang dikehendaki dunia kerja.

Beyer (dalam Sapriya, 2011) menegaskan bahwa ada seperangkat keterampilan berpikir kritis yang dapat digunakan dalam studi sosial atau untuk pembelajaran disiplin ilmu-ilmu sosial. Keterampilan-keterampilan tersebut adalah: 1). Membedakan antara fakta dan nilai dari suatu pendapat; 2). Menentukan reliabilitas sumber; 3). Menentukan akurasi fakta dari suatu pernyataan; 4). Membedakan informasi yang relevan dari yang tidak relevan; 5). Mendeteksi penyimpangan; 6). Mengidentifikasi asumsi yang tidak dinyatakan; 7). Mengidentifikasi tuntutan dan argument yang tidak jelas atau samarsamar; 8). Mengakui perbuatan yang keliru dan tidak konsisten; 9). Membedakan antara pendapat yang tidak dan dapat dipertanggungjawabkan; 10). Menentukan kekuatan argumen.

\section{Revitalisasi Metode Pembelajaran dan Sumber pembelajaran IPS.}

Pemilihan Metode dan sumber pembelajaran IPS yang sesuai dengan materi bukanlah hal yang mudah, mengingat bahwa IPS merupakan ilmu yang sangat luas dberjalaan berkembang seiring berjalannya waktu. Pembelajaran Berbasis Kontekstual (Contextual Teaching and Learning / CTL) dan Pembelajaran Berbasis Penyelesaian Masalah (Creative Problem Solving / CPS) dianggap sebagai metode yang sangat cocok dalam proses pembelajaran IPS. 


\section{a. Pembelajaran Berbasis Kontekstual (Contextual Teaching and Learning /} CTL).

Pembelajaran kontekstual (CTL) sangat tepat diterapkan dalam pembelajaran IPS. CTL merupakan konsep belajar yang membantu guru mengaitkan materi yang diajarkan dengan situasi dunia nyata peserta didik dan mandorongnya membuat hubungan antara pengetahuan yang dimilikinya dengan penerapan dalam kehidupan nyata sebagai anggota masyarakat.

Depdiknas, (2003) mengatakan ada tujuh karakteristik pembelajaran produktif dari CTL, yaitu:

1) Konstruktivisme (Constructivism), mengembangkan pemikiran bahwa peserta didik akan belajar lebih bermakna dengan bekerja dan mengkonstruksi sendiri pengetahuan dan keterampilan barunya.

2) Bertanya (Questioning), mengembangkan sifat ingin tahu peserta didik dengan mengajukan pertanyaan.

3) Menemukan (Inquiry), melatih keterampilan berpikir kritis pada semua topik pembelajaran.

4) Masyarakat belajar (Learning Community), menciptakan kondisi kelas yang nyaman dalam proses pembelajaran.

5) Pemodelan (Modelling), menghadirkan "model" dalam pembelajaran.

6) Refleksi (Reflection), melakukan refleksi di akhir pertemuan

7) Penilaian yang sebenarnya (Authentic Assessment), melakukan penilaian dengan berbagai cara yang objektif.

\section{b. Pembelajaran Berbasis Penyelesaian Masalah (Creative Problem Solving /} CPS)

Metode pembelajaran problem solving merupakan metode pembelajaran yang mampu meningkatkan kemampuan peserta didik dalam berpikir tingkat tinggi (Wiederhold dalam Suyitno, 2004). Hal ini terjadi karena metode pembelajaran problem solving memberikan kesempatan seluas-luasnya kepada peserta didik untuk memecahkan masalah terkait dengan strateginya sendiri. Salah satu pengembangan dari model pembelajaran ini adalah model pembelajaran Creative Problem Solving (CPS). 
Model pembelajaran CPS adalah suatu model pembelajaran yang melakukan pemusatan pada pengajaran dan keterampilan pemecahan masalah, kemudian diikuti dengan penguatan keterampilan. Ketika dihadapkan pada suatu masalah, peserta didik dapat melakukan keterampilan memecahkan masalah untuk memilih dan mengembangkan tanggapannya, tidak hanya dengan cara menghafal (Pepkin, 2004).

Kedua metode pembelajaran ini dapat meningkatkan keterampilan berpikir kritis peserta didik karena metode ini memberikan kesempatan kepada peserta didik untuk memecahkan masalah yang terjadi sesuai dengan kemampuan dan keterampilan mereka dalam mengolah masalah-masalah dengan teori yang ada sehingga menghasilakn sebuah solusi untuk mengatasi permasalaha yang mereka hadapi itu.

\section{Revitalisasi Proses Penilaian dalam pembelajaran IPS.}

Hasil belajar yang harus dicapai peserta didik dalam pembelajaran IPS adalah kompetensi. Kompetensi tersebut dapat berbentuk pengetahuan, sikap, keterampilan, minat, dan kebiasaan (habit). Sementara, saat ini penilaian/ asessment yang terjadi adalah peserta didik "dibiarkan" tidak menguasai apa yang seharusnya menjadi hasil belajarnya, oleh karena itu, proses penilaian IPS harus segera diperbaiki. Dalam penilaian hasil belajar IPS, guru harus mendapatkan informasi yang akurat tentang tingkat pencapaian peserta didik, melakukan perbaikan jika belum memenuhi persyaratan minimal, dan memiliki informasi yang akurat mengenai materi yang sulit dikuasai peserta didik. Perubahan orientasi dan pelaksanaan asesmen ini mutlak dilakukan dalam implementasi kurikulum IPS berbasis kompetensi.

Prinsip yang harus digunakan dalam asesmen hasil belajar adalah asesmen ditujukan untuk mengumpulkan informasi mengenai tingkat penguasaan kompetensi dan diarahkan untuk membantu peserta didik yang mengalami masalah belajar. Asesmen tidak boleh dijadikan alat untuk menghukum peserta didik. Asesmen adalah alat guru dan peserta didik untuk memperbaiki kesulitan belajar dan tingkat pencapaian kompetensi peserta didik. Untuk itu dapat digunakan berbagai model asesmen hasil belajar yang mampu memberikan informasi hasil belajar tersebut seperti SOLO Taksonomy dan Performance assessment, dan port- folio assessment yang banyak menggunakan butir soal bentuk uraian. Untuk mendapatkan informasi mengenai 
pemahaman dan ingatan terhadap berbagai fakta penting dapat digunakan tes dengan bentuk soal objektif dan portfolio assessment.

\section{SIMPULAN}

Revitalisasi pembelajaran IPS bertujuan untuk mencari solusi untuk mengembalikan mata pelajaran IPS kembali kepada tujuan awalnya. Salah satu keterampilan yang dapat dilatih dan meningkatkan adalah keterampilan berfikir kritis sebagai bekal peserta didik dalam kehidupan bermasyarakat. Konten (muatan) pembelajaran IPS, metode dan sumber pembelajaran IPS, serta proses penilaian pembelajaran IPS merupakan beberapa hal yang harus direvitalisasi.

Revitalisasi konten (muatan) kurikulum dimulai dari merubah pembelajaran yang selama ini berpusat kepada guru (teacher center) menjadi berpusat kepada peserta didik (student center). Selain itu, pemilihan materi juga sangat mempengaruhi proses pembelajaran, karena selama ini materi yang diberikan masih sangat konvensional (berupa teori, konsep, fakta, pendapat, dan sebagainya). Seharusnya pembelajaran IPS saat ini dikembangkan berdasarkan berbagai permasalahan yang ada dalam masyarakat di sekitarnya, (nasional, regional, dan dunia).

Revitalisasi metode dan sumber pembelajaran IPS dengan mencari metode pembelajaran yang tepat untuk meningkatkan keterampilan berfikir kritis peserta didik. Metode Kontekstual (Contextual Teaching and Learning / CTL) dan Pembelajaran Berbasis Penyelesaian Masalah (Creative Problem Solving / CPS) dianggap sebagai metode yang sangat cocok dalam proses pembelajaran IPS karena metode ini memberikan kesempatan kepada peserta didik untuk memecahkan masalah yang terjadi sesuai dengan kemampuan dan keterampilan mereka dalam mengolah masalah-masalah dengan teori yang ada sehingga menghasilkan sebuah solusi untuk mengatasi permasalaha yang mereka hadapi

Revitalisasi proses penilaian dalam pembelajaran IPS juga harus dilakukan karena selama ini penilaian yang dilakukan hanya sisi kognitifnya saja, sementara afektif dan psikomotor tidak terlalu diperhatikan. Oleh karena itu, pemilihan proses penilaian juga akan sangat menentukan apakah pembelajaran yang dilakukan sesuai atau tidak sesuai dengan tujuan yang telah ditetapkan diawal pembelajaran. 


\section{DAFTAR PUSTAKA:}

Departemen Pendidikan Nasional. (2003). Pendekatan Kontekstual. Jakarta: Departemen Pendidikan Nasional.

Hasan, Said Hamid. (2007). Revitalisasi Pendidikan IPS Dan Ilmu Sosial Untuk Pembangunan Bangsa. UPI. Makalah Seminar Nasional Revitalisasi Pendidikan IPS, UPI, Bumi Siliwangi.

NCSS. (2010). National Curriculum Standards For Social Studies: A Frame Work For Teaching, Learning, And Assessment.Washington, DC:Author.

Nurhadi. (2003). Pendekatan Kontekstual. Jakarta : Departemen Pendidikan Nasional

Paul, R., \& Elder, L. (2007). A guide for educators to critical thinking competency standards. Dillon Beach, CA; Foundation for Critical Thinking.

Pepkin K.L. (2004). Creative Problem Solving In Math. Tersedia di: http://www.uh.edu/hti/cu/2004/v02/04.html.

Sapriya. (2011). Pendidikan IPS Konsep dan Pembelajaran. Bandung: Rosda.

Suyitno. (2004). Pemilihan Model-model Pembelajaran dan Penerapannya di Sekolah. Semarang:Pendidikan Matematika FMIPA UNNES

Undang-Undang No. 2 Tahun 2003 Tentang Sistem Pendidikan Nasional. 